\section{Commentary: Pumps for pEF}

\author{
Daniel Burkhoff, MD, PhD
}

There are a large number of patients with severe heart failure who have normal left ventricular (LV) systolic function with small, normal, or minimally dilated LV cavities: heart failure with preserved ejection fraction (HFpEF). This population is composed of heterogeneous groups of patients, all with limited therapeutic options. ${ }^{1,2}$ Very broadly, one HFpEF subgroup (group A) is characterized by severe diastolic dysfunction and includes patients with restrictive, amyloid, sarcoid, and other infiltrative cardiomyopathies. Another, larger subgroup (group B) includes patients with 1 or more comorbid conditions, most notably including hypertension, diabetes, renal dysfunction, anemia, and obesity. Although both groups have elevated left atrial (LA) pressures and enlarged LA chambers, they differ in other important aspects. Group A patients are characterized by very small volume, thick-walled LV chambers, normal-to-low blood pressure, and low cardiac output. Group B patients can have normal or elevated blood pressure and cardiac output at rest but are unable to increase cardiac output during exercise. Since, among both groups, there are patients with severe effort intolerance, frequent heart failure hospitalizations, and increased risk of mortality, it has been proposed that some patients with HFpEF might benefit from mechanical circulatory support (MCS) devices.

In this edition of the Journal, Fukamachi and colleagues ${ }^{3}$ describe a novel left atrial assist device (LAAD) for treating HFpEF. In contrast to typical MCS configurations, this device is intended to be placed in the mitral position and pump blood from the left atrium to the left ventricle. This approach is based on the premise that increasing mitral flow will simultaneously decompress the LA (also decreasing pulmonary venous pressure) and boost filling

\footnotetext{
From the Heart Failure, Hemodynamics and Mechanical Circulatory Support Research, Cardiovascular Research Foundation, New York, NY.

Disclosures: Author reports unrestricted institutional educational grant from Abiomed and consultant fees from ReliantHeart and Medtronic.

Received for publication Jan 25, 2020; accepted for publication Jan 26, 2020; available ahead of print Feb 7, 2020.

Address for reprints: Daniel Burkhoff, MD, PhD, Heart Failure, Hemodynamics and Mechanical Circulatory Support Research, Cardiovascular Research Foundation,

New York, NY 10019 (E-mail: dburkhoff@crf.org).

J Thorac Cardiovasc Surg 2021;162:127-8

$0022-5223 / \$ 36.00$

Copyright (c) 2020 by The American Association for Thoracic Surgery

https://doi.org/10.1016/j.jtcvs.2020.01.070
}

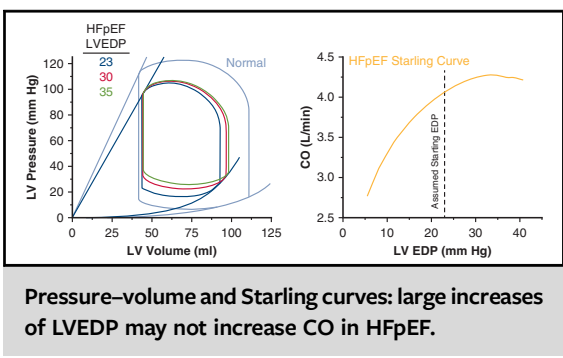

\begin{abstract}
CENTRAL MESSAGE
General commentary is provided

on the potential use of mechan-

ical circulatory support for

HFpEF patients and, more spe-

cifically, the pros and cons of a

novel left atrial assist device for

this purpose are reviewed.
\end{abstract}

to increase cardiac performance. Several critical questions arise regarding the use of MCS for HFpEF in general and regarding the proposed LAAD concept.

Relevant to Group A patients, there is already some clinical experience with traditional LV assist devices. ${ }^{4}$ Owing to the small LV chamber, inflow cannula insertion has been challenging and its position within the chamber has resulted in greater-than-usual rates of suction, arrhythmia, and pump thrombosis. Accordingly, a non-LV implant is ideal. We previously proposed pumping from the LA to the aorta with a small, partial support device, thus retaining aortic valve opening and arterial pulsatility. ${ }^{2}$ Unfortunately, that pump did not reach clinical trial in HFpEF due to unsolvable problems with pump thrombosis, possibly due to the relatively long inflow cannula and outflow graft. The LAAD avoids the later problems. While decreasing LA pressure, the question related to LAAD is how the already pressure-overload diastolic LV would respond to forced, further increases in filling. The answer to this question is not likely answered by data from the mock loop used by Fukamachi and colleagues. The issue is that, by the time these patients would qualify for MCS, they already have relatively high left ventricular end-diastolic pressures (LVEDPs). Since the end-diastolic pressure-volume relationship of these hearts are very steep, dramatic increases in LVEDP are likely to be associated with little increase in filling volume (Central Figure, left panel). Furthermore, since likely operating on the flat portion of the Starling curve, increases in LVEDP would not likely increase 
cardiac output (Central Figure, right panel). Relating this cellular physiology, even though the LV chamber is small, at high filling pressures, the sarcomeres are already stretched to (or near) their optimal lengths for force/pressure generation. None of these factors are accounted for in the artificial heart used in the mock loop, at least not based on the information provided, and effects on LVEDP were also not reported. It may be that effects demonstrated in Figures 3 through 5 of Fukamachi and colleagues overestimate effects that would be seen in the real-life setting of HFpEF.

In addition to these concerns, Group B patients typically have elevated blood pressures which, if cardiac output were increased, would be further increased by an LAAD. Elevated blood pressure has been identified as a risk factor for stroke during MCS with anticoagulation. ${ }^{5,6}$ One study showed that baseline HAS-BLED (Hypertension, Abnormal renal/liver function, Stroke, Bleeding history or predisposition, Labile international normalized ratio, Elderly [ $>65$ years], Drugs/alcohol concomitantly) score was predictive of bleeding events in patients with an $\operatorname{LVAD}^{7}$; since Group B patients are typically hypertensive and elderly, they have a minimum HAS-BLED score of 2, which was associated with $31 \%$ risk of bleeding events, one half of which included intracranial hemorrhage.

Additional questions relate to both groups. What are the implications of continuous-flow from the LA to LV regardless of the cardiac cycle phase and pins the mitral valve in an open state? What is the failure mode of this device; will a device failure prohibit flow through the mitral valve, thus creating a catastrophic event? Assuming a nonfatal failure mode can be engineered, how difficult will it be to remove or replace a device if one fails?

There is a clear unmet need and rationale for the use of MCS in some patients with HFpEF, particularly group A patients. There is much to learn from additional theoretical modeling, experimental testing, and engineering on the path to developing "pumps for pEF."

\section{References}

1. Shah SJ, Katz DH, Selvaraj S, Burke MA, Yancy CW, Gheorghiade M, et al. Phenomapping for novel classification of heart failure with preserved ejection fraction. Circulation. 2015;131:269-79.

2. Burkhoff D, Maurer MS, Joseph SM, Rogers JG, Birati EY, Rame JE, et al. Left atrial decompression pump for severe heart failure with preserved ejection fraction: theoretical and clinical considerations. JACC Heart Fail. 2015;3:275-82.

3. Fukamachi K, Horvath DJ, Karimov JH, Kado Y, Miyamoto T, Kuban BD, et al. Left atrial assist device to treat patients with heart failure with preserved ejection fraction: initial in vitro study. J Thorac Cardiovasc Surg. 2021;162:120-6.

4. Topilsky Y, Pereira NL, Shah DK, Boilson B, Schirger JA, Kushwaha SS, et al. Left ventricular assist device therapy in patients with restrictive and hypertrophic cardiomyopathy. Circ Heart Fail. 2011;4:266-75.

5. Rogers JG, Pagani FD, Tatooles AJ, Bhat G, Slaughter MS, Birks EJ, et al. Intrapericardial left ventricular assist device for advanced heart failure. $N$ Engl J Med. 2017;376:451-60.

6. Milano CA, Rogers JG, Tatooles AJ, Bhat G, Slaughter MS, Birks EJ, et al; ENDURANCE Investigators. HVAD: the ENDURANCE Supplemental Trial. JACC Heart Fail. 2018;6:792-802.

7. Kemal HS, Ertugay S, Nalbantgil S, Ozturk P, Engin C, Yagdi T, et al. Utility of CHA2DS2-VASc and HAS-BLED Scores as predictor of thromboembolism and bleeding after left ventricular assist device implantation. ASAIO J. 2017;63:720-4. 